\title{
The role of handheld spirometry in lung surgery
}

\author{
Gregor J. Kocher, Konstantinos Gioutsos \\ Division of General Thoracic Surgery, Bern University Hospital, University of Bern, Bern, Switzerland \\ Correspondence to: Gregor J. Kocher, MD. Division of General Thoracic Surgery, University Hospital Bern, CH - 3010 Bern, Switzerland. \\ Email: gregor.kocher@insel.ch. \\ Provenance: This is an invited Editorial commissioned by Executive Editor-in-Chief Jianxing He (Director of the Thoracic Surgery Department, The \\ First Affiliated Hospital of Guangzhou Medical University, Guangzhou, China). \\ Comment on: Hudson JL, Bell JM, Crabtree TD, et al. Office-Based Spirometry: A New Model of Care in Preoperative Assessment for Low-Risk \\ Lung Resections. Ann Thorac Surg 2018;105:279-86.
}

Submitted Aug 23, 2018. Accepted for publication Sep 13, 2018.

doi: $10.21037 /$ jtd.2018.09.68

View this article at: http://dx.doi.org/10.21037/jtd.2018.09.68

\section{Introduction}

The assessment of a pulmonary function prior to a major lung resection for lung cancer or other pathologies is a prerequisite for the very essential risk stratification. According to the recommendations of various societies such as the European Respiratory Society (ERS)/ European Society of Thoracic Surgeons (ESTS)/British Thoracic Society (BTS) and the American College of Chest Physicians, pulmonary function parameters should be assessed prior to any major lung resection (1-4). Although these guidelines do not differentiate between a laboratory spirometry and an office/handheld spirometry, most institutions proceed with the laboratory spirometry due to the better standardization of the examination. This eventually results to a superfluous cost, and in some cases even delay surgical therapy. In both situations, and considering that the healthcare costs are constantly on the rise, many institutions are eager to move towards a simpler and financially more reasonable preoperative assessment methods.

\section{Indications for "hand-held"/"office spirometry"}

There is no doubt that for the group of patients with significant comorbidities or challenging lung resections, a complete preoperative lung function work-up is needed. However, in patients at a low risk for postoperative complications, the implementation of an office-based spirometry instead of the standard laboratory spirometry could not only save time, but also save costs and valuable staff resources. As already shown by Puri et al. (5), office spirometry is clinically comparable to the formal laboratory spirometry and even has the tendency to rather underestimate the patient's lung function. With interest, we therefore read the recent article by Hudson et al. (6), showing that low-risk patients who underwent lung resections can be assessed adequately and safely with an office spirometry with significant cost and time savings. Based on the findings by Licker et al. (7), who showed that the best cutoff value of the $1^{\text {st }}$ second forced expiratory volume (FEV1) was $60 \%$ in terms of predicting the respiratory complications after lung surgery, in the Hudson study patients with a FEV1 greater than $60 \%$ were considered to be at a low risk for postoperative pulmonary complications. Therefore, if FEV1\% was less than $60 \%$, patients underwent a formal laboratory spirometry.

With the pressure of increasing healthcare costs over the last years, and the boiling issue of superfluous medical tests, this topic appears to be of great importance. Various handheld spirometers are validated and office spirometry is nowadays a reproducible and reliable assessment method (5,8-11) and clinically comparable to laboratory spirometry, though remaining definitely more cost and time efficient.

According to the preoperative values that are measured, and the number of segments planned to be resected the predicted postoperative (PPO) FEV1 and diffusion capacity for carbon monoxide (DLCO) can be calculated using the well-established equation. In the daily practice, these calculated values define to a high degree whether a patient qualifies for surgery or not. The postoperative predicted 
pulmonary reserve based on the preoperative pulmonary function assessment, is one of the most important criteria when evaluating patients for a lung resection (12).

This step towards a much faster and simpler evaluation method with very much comparable results would thus allow to release time and resources, which can again be invested in more complicated patients that need a more thorough preoperative pulmonary evaluation. Any patient that is considered to be at increased risk for postoperative complications, or planned for more complex procedures, such as pneumonectomy or sleeve resection, should be further evaluated by a cardiopulmonary exercise test such as an ergospirometry, and in some cases, even an additional ventilation-perfusion scintigraphy should be done (3).

Certainly, this so-called 'low risk category' of patients should be defined carefully considering their comorbidities, past medical history and the extent of the lung resection planned. Once the indication for the lung resection is confirmed, even during the first contact with the patient, and even before planning the preoperative work-up, a risk stratification can be done in order to sort out the patients that qualify for a smaller, simpler, and faster pulmonary function evaluation. Simple questions with reference to typical all-day activities can serve this cause very well. For example, the ability to climb $>2$ flights of stairs without having to stop and without shortness of breath, which was applied as an inclusion criterion in the study mentioned. It is a simple question, which can be answered clearly, although some flaws exist. The use of low-technology exercise tests such as climbing stairs, the shuttle walk test or 6-minute walk test has a place in the assessment of patients with pulmonary function values that are marginally poorer than the cut off values recommended.

Nevertheless, another important aspect in respect to the handheld office spirometry is the standardization of the whole procedure, in order to have results that are trustworthy and reproducible. The learning curve and appropriate training methods of the personnel so that they must be familiar with the spirometer, is also relevant. Otherwise, the quality of the pulmonary volume values measurements would be questionable.

Furthermore, in addition to the preoperative pulmonary evaluation, bedside spirometry has been proven to be a useful adjunct for also individuals in the early, postoperative period for an early recognition of postoperative pulmonary complications after lung resections (13).

\section{Conclusions}

With the increasing cost pressures in the healthcare system, it is out of the question that a simpler and faster evaluation method such as a handheld spirometry will replace formal laboratory spirometry, at least in the work-up of low risk patients for pulmonary resections. In patients with poorer lung function (i.e., FEV1pred $<60 \%$ ), formal laboratory spirometry still has its place due to its higher degree of standardization. In addition to the preoperative work-up, handheld spirometry also seems to be a good and easy tool for monitoring the patient's lung function in the postoperative period after surgical lung resection, eventually serving as a tool for the early recognition of postoperative pulmonary complications.

\section{Acknowledgements}

None.

\section{Footnote}

Conflicts of Interest: The authors have no conflicts of interest to declare.

\section{References}

1. Tanoue LT. Preoperative evaluation of the high-risk surgical patient for lung cancer resection. Semin Respir Crit Care Med 2000;21:421-32.

2. Salati $M$, Brunelli A. Risk stratification in lung resection. Curr Surg Rep 2016;4:37.

3. Brunelli A, Kim AW, Berger KI, et al. Physiologic evaluation of the patient with lung cancer being considered for resectional surgery: Diagnosis and management of lung cancer, 3rd ed: American College of Chest Physicians evidence-based clinical practice guidelines. Chest 2013;143:e166-90S.

4. British Thoracic Society; Society of Cardiothoracic Surgeons of Great Britain and Ireland Working Party. BTS guidelines: guidelines on the selection of patients with lung cancer for surgery. Thorax 2001;56:89-108.

5. Puri V, Zoole JB, Musick J, et al. Handheld office-based spirometry versus laboratory spirometry in low-risk patients undergoing lung resection. Innovations (Phila) 2011;6:257-61.

6. Hudson JL, Bell JM, Crabtree TD, et al. Office-Based 
Spirometry: A New Model of Care in Preoperative Assessment for Low-Risk Lung Resections. Ann Thorac Surg 2018;105:279-86.

7. Licker MJ, Widikker I, Robert J, et al. Operative mortality and respiratory complications after lung resection for cancer: impact of chronic obstructive pulmonary disease and time trends. Ann Thorac Surg 2006;81:1830-7.

8. Gerbase MW, Dupuis-Lozeron E, Schindler C, et al. Agreement between spirometers: a challenge in the followup of patients and populations? Respiration 2013;85:505-14.

9. Ferguson GT, Enright PL, Buist AS, et al. Office spirometry for lung health assessment in adults: A consensus statement from the National Lung Health Education Program. Chest 2000;117:1146-61.

10. Rebuck DA, Hanania NA, D'Urzo AD, et al. The accuracy

Cite this article as: Kocher GJ, Gioutsos K. The role of handheld spirometry in lung surgery. J Thorac Dis 2018;10(Suppl 33):S3954-S3956. doi: 10.21037/jtd.2018.09.68 of a handheld portable spirometer. Chest 1996;109:152-7.

11. Liistro G, Vanwelde C, Vincken W, et al. COPD Advisory Board. Technical and functional assessment of 10 office spirometers: a multicenter comparative study. Chest 2006;130:657-65.

12. Brunelli A, Charloux A, Bolliger CT, et al. ERS/ESTS clinical guidelines on fitness for radical therapy in lung cancer patients (surgery and chemo-radiotherapy). Eur Respir J 2009;34:17-41.

13. Kocher GJ, Gioutsos KP, Ahler M, et al. Perioperative Lung Function Monitoring for Anatomic Lung Resections. Ann Thorac Surg 2017;104:1725-32.

(English Language Editor: Jeremy Dean Chapnick, AME Publishing Company) 